
Año: 2018

DOI: https://doi.org/10.51743/cpe.42

\title{
Populismo y política democrática europea: $\tan$ cerca y $\tan$ lejos
}

Populism and european democratic politics: so close and so far

JUAN CARLOS JiMÉNEZ REDONDO

Universidad CEU San Pablo de Madrid

RESUMEN: La relación entre populismo y democracia es profundamente contradictoria. Por un lado, el populismo apela a la democracia en un sentido radical, asumiendo una posición tendencialmente autoritaria y de anulación de esa democracia que dicen defender. Por otro, la retórica populista se puede entender como un proceso de radical y permanente tensión de politización de todos los aspectos de la vida, defendiendo retóricamente esa politización como una expresión de democracia real. Esta contradicción no puede esconder que en sus términos esenciales, el populismo es y constituye una negación de la política democrática, entendida ésta como el debate y conciliación de opciones políticas e ideológicas diversas que asumen el consenso como necesario elemento básico a partir del cual asumir el pluralismo y heterogeneidad de las sociedades actuales estableciendo unos postulados comúnmente aceptados.

Palabras Clave: Populismo, Teoría política, Democracia, Comunicación Política, Espacio Público

ABSTRACT: The relationship between populism and democracy is profoundly contradictory. On the one hand, populism appeals to democracy in a radical sense, taking on a position that tends to be authoritarian, with the annulment of that democracy they claim to defend. On the other hand, populist rhetoric can be understood as a process of radical and permanent tension of politicization of all 
aspects of life, and rhetorically defending that politicization as an expression of true democracy. This contradiction cannot hide that in its essential terms, populism is and constitutes a denial of democratic politics, where this is understood as the debate and conciliation of diverse political and ideological options that adopt consensus as a necessary basic element. From this consensus the pluralism and heterogeneity of current societies can be built, through the establishment of commonly accepted assumptions.

Keywords: Populism, political theory, democracy, political communication, public sphere

\section{INTRODUCCIÓN: POPULISMO, UN CONCEPTO INAPRENSIBLE}

$\mathrm{L}$ a relación entre populismo y democracia es, a la vez, muy cercana y muy lejana. Buena parte de esta aparente contradicción tiene su razón de ser en la complejidad del concepto, pues no solo no existe una definición ampliamente aceptada de lo que es populismo, sino que sus distintas manifestaciones y sus diversas naturalezas ideológicas han acabado por desligar, de forma significativa, las aproximaciones que se hacen en la literatura científica con el significado que tiene en el lenguaje común que lo ha divulgado. Bien es verdad que no es una característica única del populismo pues, por ejemplo, el concepto de fascismo ha seguido idéntica dinámica de descontextualización y recontextualización ${ }^{1}$. Indudablemente, el término fascista ya no se refiere a un determinado tipo de régimen político típico del periodo de entreguerras, o a un movimiento político específico, ni tampoco a una concreta ideología caracterizada por unos rasgos claramente individualizados. Hoy se utiliza de forma bastante inexacta para referirse a cualquier sistema autoritario de derechas e, incluso, se ha convertido en un mero y pueril insulto que se dirige a cualquiera que se identifica con la derecha política 0 , simplemente con aquél al que se quiere descalificar políticamente acusándole de "autoritario".

\footnotetext{
${ }^{1}$ La referencia a Koselleck sigue siendo obligada, R. KoselLECK, (2012), Historias de conceptos. Estudios sobre semántica y pragmática del lenguaje político y social. Madrid, Trotta.
} 
Con el populismo ha ocurrido algo parecido, pues los intentos de aproximación teórica, insatisfactorios en buena media, han sido eclipsados por una confusa socialización del concepto que tiende a equipararlo con un genérico "decir a la gente lo que en cada momento quiere oír", lo que de ser cierto, haría del populista un extraordinario intérprete de la realidad social y un excelente y sagaz adivino de la evolución, muchas veces apresurada y vacua, de la opinión pública. Esta interpretación remite a una de las principales confusiones a la hora de delimitar lo que es una política populista y lo que es una política popular. Diferenciación tan tenue que ha llevado a autores como Benjamín Arditi a afirmar apresuradamente que, en realidad, toda política tiene algo de populista ${ }^{3}$, lo cual solo es cierto en parte; en realidad, en una muy pequeña parte. La confusión expresa, en el fondo, la profunda pauperización del concepto, al ser utilizado para referirse prácticamente a cualquier cosa, lo que conlleva el riesgo de que, en la práctica, deje de tener significado real alguno ${ }^{4}$.

De forma mayoritaria, el concepto populismo tiende a ser percibido desde una perspectiva despectiva, especialmente desde algunos ámbitos como la economía, para cuyas escuelas liberales cualquier medida de gasto público que toman los políticos con, desde su punto de vista, el único fin de ganar votos para las siguientes elecciones serían medidas populistas, pues se apartan de lo que idealmente estos economistas consideran medidas necesarias para la economía. Por ejemplo, no aumentar el salario mínimo, no incrementar el gasto público, o no llevar a cabo ciertas políticas de subvenciones a favor de determinados colectivos sea cual sea su situación. Véase que esta concepción parte de la idea de que es populista todo lo que se aparta de una determinada ortodoxia teórica, que por sí y en sí misma beneficia supuesta-

${ }^{2}$ Contrástese con la célebre frase de George Orwell "la libertad de expresión es decir a la gente lo que no quiere oír”. G. ORwell (2001) (1945) Rebelión en la granja. Madrid, Espasa-Calpe.

${ }^{3}$ B. ARDiti (2004), El populismo como espectro de la democracia: una respuesta a Canovan. Revista Mexicana de Ciencias Políticas y Sociales, vol. 47, nº. 191, pp. 105-120.

${ }^{4}$ M. Canovan, (1999) Trust the People! Populism and the Two Faces of Democracy. Political Studies, Xol. 47-1, pp. 2-16; G. Hermet (2003): El populismo como concepto. Revista de Ciencia Politica. Vol. XXIII-1, pp. 5-18; J.N. Muller (2016), What is populism? Filadelfia, University of Pennsylvania Press. 
mente a la economía en términos teóricos y abstractos, lo que de acuerdo a una lógica subyacente no siempre fácil de comprobar, significaría necesariamente beneficiar al mayor número de personas posible.

Pero el populismo es otra cosa, pero ¿qué otra cosa? Para unos, un estilo político, para otros, una estrategia política o un instrumento electoral. Seguramente es todo eso, pero lo que desprende su esencia es su naturaleza de discurso, lo que hoy se denominaría una estrategia de comunicación política, que en síntesis radical, se orienta a exaltar la irracionalidad y la emocionalidad como elementos a partir de los cuales inventar una sociedad radicalmente segmentada entre una elite y un pueblo, cuyo único representante e intérprete legítimo sería ese líder populista. Desde esta perspectiva, el populismo es, esencialmente, iliberal ${ }^{5}$, y como tal, su objetivo es agudizar el proceso de desinstitucionalización de las democracias occidentales a través de instrumentos retóricos y simbólicos de aceleración de la crisis de representación que estas democracias sufren desde hace años.

En otras palabras, el populismo europeo del siglo XXI tiene, a pesar de su doble naturaleza de radicalidad izquierdista y de radicalidad identitaria, un punto de encuentro, como es su común intención de acabar con los consensos implícitos y explícitos solidificados desde el fin de la segunda guerra mundial por la socialdemocracia y la democracia cristiana, o si se quiere entre una derecha y una izquierda moderadas, capaces de crear amplios espacios de acuerdo que durante décadas han garantizado la convivencia, el orden social y la socialización masiva de los frutos del crecimiento económico. Por eso, este neopopulismo posmoderno tiene una significación propia y específica que lo hace en buena medida diferente de las experiencias populistas históricas, aunque, por supuesto, beben en sus experiencias, logros y

\footnotetext{
${ }^{5}$ Pappas caracteriza el populismo como un nuevo subtipo de democracia, cuya característica esencial es su crítica antiliberal. T.S PAPPAS (2014) Populist Democracies: PostAuthoritarian Greece and Post-Communist Hungary. Government and Opposition, vol. 491, pp. 1-23, DOI:10.1017/gov.2013. Una discusión general y una revisión bibliográfica en profundidad en F. VAllespín y M. MARTínez-Bascuñán (2017), Populismos. Madrid, Alianza Editorial; N. GIDRON y B. BONIKOSKI (2013), Varieties of populism: Literature review and research agenda. Working Paper Series $n^{\circ} .13-0004$, Weather Center for International Affairs, Harvard University.

http://scholar.harvard.edu/files/gidron_bonikowski_populismlitreview_2013.pdf
}

ISSN 02140284

Cuadernos de pensamiento 31 (2018): pp. 77-102 
fracasos. En definitiva, el populismo nunca ha dejado de reproducirse a partir de retomar conceptos y prácticas anteriores, aunque reconvertidos de acuerdo a las nuevas necesidades y las nuevas perspectivas de coyunturas históricas evolucionadas y, por tanto, diferentes.

En este trabajo nos centraremos en el radicalismo populista de izquierdas, los que han aflorado con más fuerza en el Sur de Europa, dadas las características estructurales de este espacio, mientras que los radicalismos identitarios y etnicistas lo han hecho en el centro y norte de Europa. Aunque no conviene hacer distinciones radicales, pues si bien es cierto que España y Portugal siguen de forma clara esta distinción, Italia y Grecia no lo hacen, al existir en ambos países potentes radicalismos populistas tanto identitarios como de extrema izquierda. Incluso Italia presenta la peculiaridad de que ambos polos populistas han conformado un consenso lo suficientemente fuerte como para conformar una coalición de gobierno.

\section{LA HERENCIA DEL POPULISMO CLÁSICO: LAS APORTACIONES LATINOAMERICANAS A LA CONSTRUCCIÓN DE LA IZQUIERDA POPULISTA}

Dejando al margen los primeros movimientos populistas americanos y rusos, el populismo ha sido tradicionalmente asociado a los grandes líderes latinoamericanos de los años treinta y cuarenta como el brasileño Getúlio Vargas o el argentino Juan Domingo Perón. Dos regímenes que, curiosamente, o no tanto, oscilaron profundamente en toda la línea definida por ese eje ideológico derecha/izquierda, hasta el punto de quitarle todo contenido real ${ }^{6}$.

En general estos populismos clásicos han sido analizados de forma dispar. Para la historiografía liberal se trató de regímenes personalistas, de fuerte tendencia autoritaria, que rompieron las ya entonces muy precarias instituciones liberales existentes. Por ello los catalogan como regímenes de ruptura de la democracia $^{7}$. Por su parte, las perspectivas estructural-funcionalistas y las de base

\footnotetext{
${ }^{6}$ A. Rivero; J. Zarzalejos y J. Del PAlacio (Coords.) (2017) Geografía del populismo: Un viaje por el universo del populismo desde sus orígenes hasta Trump. Madrid, Tecnos.

${ }^{7}$ E. Bohoslavsky y M. Vicente (2014), El Estado Novo a ojos de liberales de Argentina y
} 
marxista hablaron de ellos como experiencias modernizadoras típicas de un momento de atraso económico, que tuvieron la virtud de incorporar al sistema político a grandes masas de población hasta esos momentos marginadas. Desde esta perspectiva se asocia la aparición de los regímenes populistas al desarrollo del capitalismo dependiente y a la actuación política de sectores populares que buscaban abrir un sistema político cerrado ${ }^{8}$. Es decir, no serían sino intentos de los países latinoamericanos para controlar los procesos de modernización determinados desde el exterior, haciendo que el Estado ocupara un lugar central en la defensa de la identidad nacional y en la promoción de la integración nacional a través del desarrollo económico y de la superación del conflicto interno por medio de la negación del concepto de lucha de clases ${ }^{9}$.

Desde esta perspectiva se interpretó que los populismos habían favorecido la democracia, por lo menos la democracia social, aunque sus prácticas políticas se hubieran apartado de la ortodoxia de la democracia política liberal. Es decir, los populismos habrían sido experiencias de democracia social que sobrepasaron el concepto tradicional de democracia liberal. El argentino Gino Germani lo sintetizaba de forma clara cuando consideraba que los populismos asumieron la forma de movimientos nacionales interclasistas de base popular que asumieron la función de dar una respuesta al principal problema que una transición de este tipo conllevaba: los problemas de redistribución en una economía y una sociedad más complejas y con nuevas demandas de reconocimiento y participación. Esta interpretación no dejaba de resaltar el grado de manipulación que el líder populista ejercía sobre las masas, apartándolas así de sus intereses y objetivos de clase ${ }^{10}$, pero aunque era

de Brasil (1937-1946). Revista de Historia Contemporánea, vol. 8-2, pp. 226-253. E. Krauze (2018), El pueblo soy yo. Médixo, Editorial Debate. Un análisis general del populismo desde esta perspectiva liberal en A. VARgas Llosa (coord.) (2017), El estallido del populismo. Barcelona, Planeta.

${ }^{8}$ F. Freidenberg, (2006), La tentación populista: una vía al poder en América Latina. Madrid, Editorial Síntesis, p. 12. C. DE LA TORRE (2001), Redentores populistas en el Neoliberalismo: nuevos viejos populismos latinoamericanos. Revista Española de Ciencia Política, $\mathrm{n}^{\circ} .4$, pp. 171-196.

${ }^{9}$ A. Touraine, (1989) América Latina. Política y sociedad. Madrid, Espasa-Calpe.

${ }^{10}$ G. Germani, (1962), Politica y sociedad en una época de masas: de la sociedad tradicional a la sociedad de masas. Buenos Aires, Paidós. 
una apreciación interesante no relaja la rigidez de su perspectiva, ya que únicamente aceptaba que la clase obrera tenía un único interés racional: la socialización de los medios de producción.

En todo caso, lo importante es resaltar cómo incluso desde posiciones marxistas, y cómo a pesar de reconocer que los regímenes populistas lograron algunos avances estructurales significativos, en términos generales, siguió predominando una valoración despectiva del fenómeno, al considerarlo una cierta degradación de la democracia. Una interpretación negativa que, esencialmente, Ernesto Laclau, tanto en solitario como en compañía de Chantal Mouffe, intentó cambiar al considerar el populismo como un instrumento a partir del cual recrear la definición de un nuevo posmarxismo $^{11}$. Una reconstrucción de la izquierda que retomaba elementos típicos de esos regímenes latinoamericanos de mediados del siglo XX. Por ejemplo, la aceptación de la tópica denuncia populista del sistema oligárquico latinoamericano del siglo XIX y la necesidad de asimilar las nuevas fuerzas sociales en emergencia a través de la nueva función interventora del Estado dentro de un modelo de desarrollo de industrialización por sustitución de importaciones.

En realidad, no es más que la recreación permanente del mito de la dependencia, eje de articulación de todas las alternativas iliberales surgidas en América Latina desde los años treinta, por cuanto fue la que proporcionó ese recurso retórico nacionalista y anti-imperialista propio de todas ellas ${ }^{12}$. Porque el populismo clásico recurrió permanentemente a la denuncia del sistema internacional, -el sistema imperial desde su perspectiva- no solo como recurso legitimador externo de estos regímenes, sino también interno, aunque en realidad, era un mero justificante discursivo de su limitada capacidad desarrollista. Es decir, sus propios fracasos

${ }^{11}$ E. LaClau y CH. MoufFe (1987), Hegemonía y estrategia socialista. Hacia una radicalización de la democracia. Madrid, Siglo XXI.

${ }^{12}$ De entre toda la abundante bibliografía de referencia, algunas de las más emblemáticas son, F.H. CARdoso y E. Faletto (1969), Dependencia y desarrollo en América Latina. México, Siglo XXI. V. BAmBirRa (1986), El capitalismo dependiente latinoamericano, Siglo XXI, México. T. Dos SAntos (2003). La teoría de la dependencia: balance y perspectivas. Buenos Aires, Plaza\&Janés, Buenos Aires. A. Gunder Frank (1970) Capitalismo y subdesarrollo en América Latina. Buenos Aires, Siglo XXI. 
siempre fueron achacados a un enemigo externo, esto es, a un sistema considerado explotador e injusto, a un sistema mundial de dominio imperial que no permitía a estos países desarrollarse y que contaba en el interior con el apoyo de esa "oligarquía antinacional" que operaba contra los verdaderos intereses del pueblo.

Indudablemente, en esos años treinta y cuarenta, la posibilidad de articular un discurso de radical polarización entre el pueblo y la oligarquía no hubiera tenido sentido fuera de un contexto agudo de crisis como el vivido a partir de 1929. Momento, por supuesto, de crisis económica; pero no solo de crisis económica, sino también de crisis política, ideológica e institucional. Este tipo de crisis rompe los apegos institucionales creados y permite el cuestionamiento radical de la política y de lo político, además de hipertrofiar las demandas de seguridad de una población caracterizada por el miedo y la incertidumbre. El avance social experimentado en el último cuarto del siglo XIX y el primer decenio del XX había cuestionado la virtualidad de los viejos dogmas marxistas de la lucha de clases y de la pauperización progresiva e irreversible del proletariado, pero no había eliminado la sensación de inseguridad que seguía atenazando a buena parte de las sociedades. Es, precisamente eso lo que amplifica la crisis de finales de la década de los veinte, convirtiéndola en verdadera obsesión que para muchos sectores sociales solo podía ser paliada a través de regímenes fuertes, en muchos casos simplemente autoritarios, que convirtieran al Estado en ese protector de unas masas que habían perdido de forma brusca la apreciable mejoría económica conseguida en los años precedentes. En otras palabras, el populismo latinoamericano clásico reconfiguró el viejo dogma marxista de la lucha de clases en términos de una nueva dinámica de encuadramiento del conflicto social dentro de un entramado socio-económico dirigista y corporativista basado en el control político del Estado.

En resumen, las experiencias populistas clásicas demostraron que sus discursos de radical polarización solamente son viables en situaciones estructurales de crisis que, a su vez, agudizan las disfuncionalidades de los sistemas liberales y de las economías de mercado. Por eso tienen éxito las llamadas populistas a la introspección nacionalista, a ideales proteccionistas e incluso autárquicos, a la culpabilidad del "otro" como causante de los problemas 
nacionales y la acusación a las clases más pudientes de ser las responsables de la crisis, de acuerdo a una exacerbación del odio social ${ }^{13}$.

\section{LA NUEVA IZQUIERDA POPULISTA: LA FALACIA DE LA ÉPICA DISCURSIVA}

Laclau ligaba el populismo con la democracia. Es más, creía que el populismo debía ser el nuevo instrumento de actuación de la izquierda con el fin de deslegitimar las estructuras capitalistas de las democracias finiseculares. Esta nueva vertiente de crítica sobre el funcionamiento del capitalismo debía, su juicio, basarse en una nueva épica iliberal asentada en una alianza de clases y movimientos sociales aglutinados en un nuevo sujeto revolucionario llamado el "pueblo" liderado por un nuevo agente de concienciación, el líder populista, depositario de un carisma y de una irreductible capacidad para conducir a ese pueblo al poder, mejor dicho, a quienes se presentan como sus únicos representantes legítimos. Por eso Laclau situaba el populismo en el terreno del discurso político. Es decir, como emanación de una retórica de polarización que dividiera a la sociedad en dos campos irremediablemente antagónicos: pueblo/oligarquía; lo que desde su punto de vista expresaba la lucha política por la democracia como manifestación de una lucha social o de clases.

$\mathrm{Su}$ apelación al pueblo unido contiene, por tanto, una profunda contradicción y una paradoja sólo comprensible en términos de violencia simbólica: el pueblo es uno, pero esta categoría solamente se puede definir depurando, extirpando o sojuzgando a quienes no son considerados como pueblo. Es decir, el populismo rompe la sociedad en dos: el pueblo y el no pueblo. El plutócrata, el oligarca, el rico, el poderoso es el anti-pueblo. Evidentemente, supone la hipertrofia de la clásica y siempre discutida concepción schmittia-

\footnotetext{
${ }^{13}$ En palabras actuales, se habla de la agudización de las contradicciones generadas por el neoliberalismo, como Marx hablaba de las contradicciones del capitalismo que debería llevar a su inapelable extinción. Esta permanente recreación de la lógica explicativa marxista y su plasmación en el populismo en CH. Delsol, (2015), Populismos. Barcelona, Ariel; M. Revelli, (2015) Posizquierda. Madrid, Trotta.
} 
na de lo político como campo específico de la dualidad amigo/enemigo ${ }^{14}$. Conlleva lo que acertadamente Laclau definió como una parcialidad que quiere funcionar como la totalidad de la comunidad ${ }^{15}$.

Este discurso es necesario para camuflar su carácter de movimiento profundamente iliberal y darle un matiz igualitarista, que no igualitario, que es percibido como esencial a la hora de cumplir su principal objetivo: la obtención del poder político. ${ }^{16}$ Como discurso de justificación es ideológicamente ambiguo, pues se dirige más a la parte emocional que a la intelectual de sus receptores. Precisamente, esa apelación permanente a lo emocional, a la irracionalidad supone negar el ideal liberal de que la política es, al contrario de lo mantenido por Schmitt, el ámbito de la racionalidad y de la moderación, de la aceptación del pluralismo y de los derechos individuales que se expresan de forma conflictiva, pero ordenada, en el espacio público democrático. Es, sin duda, este aspecto de irracionalidad, junto a la exaltación del liderazgo carismático y el valor supremo del pueblo, lo que asemeja a los populismos y neopopulismos con los fascismos. Sin embargo, es una equivalencia equivocada. Los populismos no precisan un espacio autoritario o totalitario formal, sino unas condiciones culturales que permitan dar prioridad a sus discursos y situar los asuntos de su interés como puntos esenciales de las agendas políticas. Por eso los populismos son perfectamente compatibles con la democracia, aunque para poder mantener esta idea se deba considerar ésta en sus aspectos más formales. Los populistas aspiran al poder simbólico y cultural, en términos claramente gramscianos. Alcanzar el poder político es, en esencia, la consecuencia última e inevitable de esa hegemonía ideológica.

Dicho en otros términos, el populismo del nuevo siglo XXI se define como una estrategia política de dominación comandada por unos actores que quieren llegar al poder. Esta es la idea de proceso que les aparta de los viejos partidos que querían alcanzarlo a la fuerza mediante golpes de Estado. Aun-

\footnotetext{
${ }^{14}$ C. Schmitt, (1999), El concepto de lo politico. Madrid, Alianza Editorial.

${ }^{15}$ E. Laclau (2005), La razón populista. Buenos Aires, Fondo de Cultura Económica, p. 108.

16 Wayland escribe que el populismo es "a specific way of competing for and exercising political power". K. Weyland, Kurt. Clarifying a Contested Concept Populism in the Study of Latin American Politics. Comparative Politics, vol. 34-1, pp. 1-22 (p. 11)
} 
que algunos neopopulismos han recurrido a esas fórmulas putchistas, como sucedió por ejemplo en Venezuela con Hugo Chávez Frías, la estrategia típica de los populismos del sur de Europa es considerar la política como un proceso de conquista democrática del poder, que llegará al asentar y expandir su masa social unificando demandas de grupos socialmente heterogéneos, pero que coinciden en proclamas necesariamente generales e inconcretas que crean una genérica identidad común.

El populismo puede convivir con la democracia porque al contrario que el totalitarismo no pretende construir un espacio público radical y completamente dirigido por el Estado/partido. Es una convivencia instrumental, pues la dimensión emocional de esa partición de la sociedad y la consecuente definición de una legitimación de base ideológica e irreflexiva, conlleva un proceso de construcción pausado y progresivo. Los enemigos deben estar siempre presentes. Los enemigos son derrotados, no eliminados como sucedió en los regímenes totalitarios empeñados en la construcción del mito del "hombre nuevo". Aparece aquí una nueva contradicción del populismo, solamente entendible desde su carácter de discurso político. Los populistas asumen un discurso de radicalidad democrática, pero es una apelación que al contrario de lo que afirman Abts y Rummers no es una apuesta por la democracia $^{17}$. Es lo que Gratius, refiriéndose a lo que denomina la tercera ola populista de América Latina, denomina regímenes híbridos ${ }^{18}$.

El populismo niega la libertad individual, pues considera que el pueblo, la ciudadanía en términos más actuales, es un todo integrado y armónico donde el individuo se adecúa naturalmente al supremo interés colectivo, a un bien común definido y delimitado por el movimiento y sus líderes. Quien no se integra en él es desprestigiado como antipatriota o agente vendido a un supuesto enemigo externo. Al utilizar esta forma de represión psicológica y unirla al dominio del aparato del Estado, el populismo puede convivir con un sistema formal de democracia constitucional, aunque siempre limitándola a un marco puramente formal. Para justificar esta limitación de la democracia,

${ }^{17}$ K. Abts y S. Rummens (2007), Populism versus Democracy. Political Studies, vol. 55, pp. 205-424.

${ }^{18}$ S. GRATIUs (2007), La "tercera ola populista" de América Latina. FRIDE. Documento de Trabajo, $n^{\circ} .45$. http://fride.org/publicacion/281/la- 
el discurso político populista trata de inventar justificaciones en el sentido de presentarse a sí mismos como la única y legítima representación del verdadero pueblo, lo que conlleva la deslegitimación y deshumanización radical del adversario político, reducido a la simple categoría de enemigo político.

El líder es considerado el gran conductor predestinado para dirigir los destinos del pueblo. Pero el populismo une los destinos del líder a los del pueblo. Es decir, parte de una exaltación del pueblo como categoría suprema. Un pueblo idealizado liderado por un caudillo que se enfrenta a los sectores anti-populares. Para dar credibilidad a ese discurso de exaltación del pueblo, los populismos incorporan ciertos mecanismos redistributivos, utilizando al Estado como instrumento de reparto y de una cierta redistribución de la riqueza que fije la adhesión de las masas al proyecto. Pero no hay redistribución en el sentido de justicia típica de los Estados de Bienestar, sino la utilización de fondos públicos como mecanismo para generar dinámicas de clientelismo político. En realidad, la convivencia con la democracia formal es un instrumento de legitimación del movimiento populista y del liderazgo populista. No es sorprendente, pues muchos regímenes autoritarios han mantenido aspectos formales de democracia como forma de legitimación

El populismo es un voluntarismo político. Dado que la construcción ideológica real se esconde bajo el discurso populista, existe la tendencia a difuminar los programas políticos para dar cabida a apelaciones globales, a grandes referencias generales a fin de alcanzar un compromiso absoluto por parte de sus fieles. ¿Quién va a estar en contra de la paz, de la igualdad, de la inclusión social, del ecologismo o del bienestar y la protección de todos? En estos programas, se alude a un cambio total, a una revolución imaginaria que alterará radicalmente la situación anterior para dar paso a una nueva etapa idílica, -y ficticia-, creadora de lo "nuevo", aunque nunca se especifica con claridad qué es lo nuevo. El populismo apela a la unanimidad política como forma de alcanzar esa revolución en marcha y a quien no lo acepta se le tilda de traidor y antipatriota ${ }^{19}$. Al carecer de proyecto real, utiliza el nacionalismo cerrado como elemento de justificación de su poder. Para ello necesitan

\footnotetext{
${ }^{19}$ Por esa ruptura de la confrontación pluralista se le tilda de antipolítico en el sentido apuntado por G. Hermet (2003), El populismo como concepto. Revista de Ciencia Política, vol. 23-1, pp. 5-18.
} 
un enemigo exterior poderoso al que acusar de todos los males del país. Este enemigo externo es además un eterno justificador de su ineficacia, pues todos los problemas se achacan a él, ya sea la globalización, el neoliberalismo o la misma Unión Europea, acusada de ser una mera Europa de los mercaderes que ha abandonado la defensa de los intereses del pueblo europeo.

Desde esta perspectiva, los populismos generan un nuevo elemento contradictorio. Quieren el poder, es decir, son un instrumento de poder. Quieren el dominio del Estado como plataforma a través de la cual perpetuarse en el poder, pero a medio y largo plazo no favorecen la institucionalización ni la creación de un Estado útil y eficiente. Es decir, el populismo tiende a utilizar el Estado y su capacidad financiera para alimentar la red clientelar que le sirve de soporte.

Lo que sí vio Laclau con claridad es que el populismo intenta satisfacer esa revolución de las aspiraciones y demandas de los ciudadanos, en sus distintas fases, que calan por ser, esencialmente, demandas de seguridad ante escenarios de incertidumbre. Germani ya había sostenido que la respuesta populista es más aparente que real, en cuanto hablaba de experiencias simbólicas de participación en regímenes semiautoritarios ${ }^{20}$. Pero esta afirmación, junto a la de discurso, parecería llevar a la idea de que el populismo carece de ideología, Sería más bien una forma de acción política sin ideología definida o mejor, de ideología confusa o delgada ${ }^{21}$.

Sería difícil aplicar ese concepto de ideología delgada a los populismos identitarios, pero todavía lo sería mucho más si se consideran los de extrema izquierda. Este tipo de populismo parte de ideologías duras y las barniza a

${ }^{20}$ G. GERMANi (1962) Democracia representativa y clases populares. Desarrollo Económico, vol. 2-2, pp. 23-43.

${ }^{21}$ C. MudDe, (2004) The Populist Zeitgeist. Government and Opposition, vol. 29-4, pp. 541563. C. Mudde y C. Rovira Kaltwasser, (2017), Populism. A very short introduction. Oxford, University Press, Para la discusión del concepto, M. FreEden (1998), Is Nationalism a Distinct Ideology?, Political Studies, vol. 46-4, pp. 748-765. B. STANLEy (2008), The Thin Ideology of Populism. Journal of Political Ideologies, vol. 13-1, pp. 95-110. P. Taggart (2000), Populism. Buckingham, Open University Press. J. Jagers y S. WaLGRAVE (2007), Populism as political communication style. An empirical study of political parties discourse in Belgium. European Journal of Political Research, vol. 46-3, pp. 319 345 . 
través de un determinado tipo de discurso, y de un proceso comunicativo de polarización moral, política, ideológica y social cuyo objetivo es segmentar radical y permanentemente a la sociedad en un nosotros y un ellos.

\section{EL DISCURSO POPULISTA QUE PRETENDE ESCONDER LA IDEOLOGÍA}

Los actuales populismos se pueden definir como discursos de simplificación de la política y de amplificación del antagonismo social que encubren proyectos ideológicos duros, que utilizan instrumentalmente el discurso populista para alcanzar una relevancia política que no tendrían en caso de no camuflar esa ideología rectora a través de esa retórica populista. Por tanto, el populismo es el instrumento comunicativo de unos radicalismos, en unos casos étnicos y en otros de naturaleza neomarxista, posmarxista si se quiere, que permiten dar a esos discursos la apariencia de una preocupación por el bienestar de las masas, cuando realmente son estrategias comunicativas y de ruptura institucional creadas para alcanzar el poder y desde él crear una estructura clientelar que les asegure su conservación y su imposición ideológica. En otras palabras, son estrategias retóricas encaminadas a incrementar la fragilidad de la democracia liberal para alcanzar y capitalizar el poder.

Esta retórica populista es lo que iguala discursos cuya esencia y objetivos son, sin embargo, muy diferentes. Seguramente, si se analizan los discursos del presidente norteamericano Donald Trump y de Unidos Podemos, o los del Rassemeblement National y el viejo discurso de Syriza se encontrarán apreciables semejanzas. Todos ellos hablan de la vieja política como un charco de corrupción que hay que eliminar; todos ellos dicen representar al verdadero pueblo americano, español, francés o griego; todos ellos segmentan y dividen radicalmente la sociedad en términos morales: los buenos, los míos; los malos, los otros; y todos ellos, en fin, apelan al orgullo nacional, a la idea de soberanía o atacan por igual la globalización por injusta, neoliberal, o porque favorece a los extranjeros frente a los nacionales. 
Pero estas coincidencias no pueden esconder diferencias radicales. La fundamental, que la idea de pueblo en la extrema izquierda populista es inclusiva en términos étnicos, es decir, en términos de identidad; pero es excluyente y radicalmente excluyente en términos sociales porque deja fuera a esa llamada elite extractiva que supuestamente está robando al pueblo. El problema es que son ellos mismos quienes dicen quién es élite y quién es pueblo. Sin embargo, el radicalismo populista identitario es excluyente en su concepto de pueblo, pues solo forma parte de él quienes han nacido en ese territorio, mientras que niegan al resto simplemente su derecho a residir en sus países. Es decir, si ambos radicalismos son nacionalistas, sus ideas acerca de la nación (concepto liberal que ellos no usan) y del pueblo, y de quienes los componen son radicalmente diferentes, como lo son también las soluciones que proponen para el bienestar. En unos casos, es el desarrollo privado amparado por un Estado que debe volver al proteccionismo económico; en el otro, es hacer del Estado un macroente de redistribución de los ricos hacia los pobres, aunque encubriendo el objetivo real de crear una red clientelar que los mantenga en el poder ${ }^{22}$.

Volvamos a la idea del populismo como discurso iliberal. El otrora triunfante discurso de la victoria inapelable del capitalismo y de la democracia es seriamente cuestionado. Fukuyama ha dejado paso, en esta nueva izquierda populista, a una recreación de la planificación centralizada, en un discurso que convierte al Estado en el garante de la seguridad de los desfavorecidos gracias a la promesa de unas políticas redistributivas que conseguirán la siempre anhelada igualdad social. Es la utilización de la política para acabar con la política, entendiendo por tal la libre concurrencia, el pluralismo y el principio esencial de la libertad.

Porque si este populismo es algo, es una retórica contra la libertad en nombre, curiosa y contradictoriamente, de la libertad y la democracia, eso sí, ambas renombradas como "reales". En esto es profundamente antidemocrático $^{23}$. Como se ha indicado reiteradamente, los radicalismos instrumental-

\footnotetext{
${ }^{22}$ A. KaISER y G. Álvarez (2016), El engaño populista: por qué se arruinan nuestros países y cómo rescatarlos. Bilbao, Ediciones Deusto.

${ }^{23}$ J.M ${ }^{\text {a }}$. LASAlle, (2017), Contra el populismo. Cartografía de un totalitarismo posmoderno. Barcelona, Debate.
} 
mente populistas son proyectos políticos iliberales que pueden convivir con la democracia, aunque su entramado ideológico duro les empuje hacia el autoritarismo. Pero convivir no significa que no sean un instrumento para fragilizar la democracia. De hecho ese es su objetivo esencial ${ }^{24}$.

Este populismo no existiría sin una estrategia de politización permanente de la gente, para lo que es imprescindible crear un clima de fuerte tensión social. Es, otra vez, la utilización de la política para acabar con la política. Los populismos se basan en la idea del caos, cuanto peor, mejor; porque es lo que justifica y da sentido a su división radical entre buenos y malos. Una polarización, que como ya se ha indicado, remite insistentemente a Carl Smichtt, de quien estos populismos toman otros dos elementos esenciales, de claro matiz autoritario: la devaluación y supeditación del individuo en favor de la colectividad, o la contradicción que establecen entre democracia y liberalismo.

Desde la radicalidad de esta izquierda populista, se desarrolla la idea de que para que ese pueblo tome conciencia de su supuesta situación de explotación debe sufrir una permanente tensión de radicalización, aunque sustituyendo la vieja idea de lucha de clase por conceptos que suenan más posmodernos como elite o casta. En todo caso, la idea de iliberalidad alude a la tentación de desmontar y deslegitimar las instituciones representativas de la democracia liberal clásica, siempre que no las puedan fagocitar o atraer para su causa. No es solamente llamar la atención de los medios, sino que es una estrategia deliberada cuyo objetivo es desacralizar las instituciones políticas a fin de que la gente las considere contaminadas por esa elite que las acapara y, en última instancia, irrelevantes. Si las instituciones "no nos representan" gana "la calle", es decir, quien es capaz de agitar la calle bajo cualquier pre-

\footnotetext{
${ }^{24}$ La opinión de De Carreras es tajante: el populismo es un ataque contra la democracia y en caso de triunfar intentará generar un sistema distinto que ya no podría denominarse democrático. F. DE CARRERAS, Populismo contra democracia. El País, 9 de abril de 2015. http://elpais.com/elpais/2015/04/06/opinion/1428341485_453181.html.

Según Acemoglu, Egorov y Sonin, la fuerza conductora de las políticas populistas es el debilitamiento de las instituciones democráticas. D. Acemoglu, G. Egorov y K. Sonin (2011), A Political Theory of Populism. Working Papers 17306, National Bureau of Economic Research, p. 31.

http://economics.mit.edu/files/8797.
} 
texto. Si estas instituciones, el Parlamento, la prensa o la judicatura por ejemplo, asumen una posición libre e independiente sufrirán las arremetidas de estos movimientos populistas. Sin embargo, si se muestran proclives serán exaltados como arietes de la verdadera democracia, es decir, de ellos.

Pero la iliberalidad viene sobre todo de la construcción de un nuevo discurso legitimador que millones de personas parecen querer aceptar, basado en dos elementos esenciales: por un lado, echar la culpa a las elites de toda situación de injusticia o vulnerabilidad social; y, en segundo término, expandir la utopía de lo inmediato: sencillas soluciones instantáneas a los problemas, por complejos que sean éstos, cuyo elemento más característico es la acentuación del discurso redistributivo radical -quitar a unos para dárselo a otros.

Liderazgos exagerados y excesivos, hablar de todo y por todo, aunque sea a través de esa nueva arma comunicativa que son las redes sociales y que para propagar sus discursos pueden ser manejadas mediante el control de miles de robots que se encargaran de convertir esos mensajes en "trending topic". En este nuevo ámbito comunicativo, los apoyos a las propias posiciones se tienen o se fabrican, y los comentarios contrarios contribuyen fatalmente a la causa al ser sus autores acusados de fascistas $u$ otras expresiones denigratorias, con lo que curiosamente sirven básicamente para asentar la posición de partida, reforzando el sentimiento de pertenencia de sus intervinientes, y demostrando la supuesta realidad de la polarización de la sociedad: otra vez la retórica maniquea de los buenos contra los malos.

Pero no solo las redes sociales, también la televisión, que tiende a conceder un inusitado realce a este populismo. Además de las claras vinculaciones ideológicas que muchas televisiones y periodistas mantienen hacia estas propuestas ideológicas, parece claro que una parte de esta atención es debido al nuevo papel de este medio como plataforma de adaptación de la política a fórmulas de diversión y entretenimiento de masas, transformando de esta forma las clásicas formas de comunicación política. Se habla de la telenovelización $^{25}$ de la política o de la conversión de la política en un espectáculo

${ }^{25}$ En este sentido, encaja bien la sugerente idea de Fermín Bouza de telenovelización de la política. F. BOUZA Álvarez (2007), La telenovelización de la politica: (del nacionalcatoli- 
más ${ }^{26}$; un simple y simplista entretenimiento más propio de lo que durante tiempo no había muchas dudas en calificar como telebasura.

La lógica de estos programas de tertulia política o mejor, de espectáculo político, lo que realmente hace, apelando a un supuesto pluralismo, es reproducir esa polarización populista: unos tertulianos buenos y otros malos, que se chillan e insultan demostrando la imposibilidad de acuerdo alguno entre ellos; lo que es asimilado a lo que ocurre en la sociedad: dos bandos ideológicos fatalmente enfrentados y sin posibilidad alguna para comprenderse.

En definitiva, tanto las redes sociales como esta televisión no sólo son los grandes arietes de la nueva sociedad del espectáculo, si no que han obligado a pensar y definir una nueva forma de transmitir los discursos políticos en la que los componentes sentimentales y emocionales, y las posiciones maniqueas se imponen frente a narrativas basadas en la racionalidad o en la complejidad y la definición problemática de las situaciones y los procesos políticos. Es la aparición de la política líquida ${ }^{27}$, política posmoderna, o lo que se ha denominado política 2.0 o ciberpolítica.

La televisión y las redes sociales no solo generan nuevas dinámicas de debate que influyen sobremanera en la opinión pública, sino que se han convertido en una especie de miniconciencia de la sociedad que define nuevos entornos morales, nuevos criterios de lo aceptado o no socialmente y nuevos cauces de encorsetamiento de la cultura política de los ciudadanos. Por supuesto que pueden ser calificadas de limitadas, superficiales y evanescentes, pero a pesar de ello —o a lo mejor, precisamente por ello-, están redefiniendo las estructuras de pensamiento de estas sociedades líquidas posmodernas que han sustituido las grandes construcciones teóricas por superficiales y efimeros pensamientos que lo mismo que se en un momento dado se convierten en referencias que parecen alcanzar validez universal, desaparecen tan rápidamente que ni siquiera son recordados apenas unos meses después de formulados.

cismo al mirón comunitario), en Lo que hacen los sociólogos: homenaje a Carlos Moya Valgañón. Madrid, CIS, pp. 363-373.

${ }^{26}$ G. SARTORI (2012), Homo videns. La sociedad teledirigida. Madrid, Taurus.

${ }^{27}$ Asumiendo la descripción realiza por Z. BAUMAN (2002), Modernidad líquida. México, FCE, 2002. 
En todo caso, lo esencial es que la lucha por la hegemonía cultural se hace hoy desde esta perspectiva de liquidez y pensamiento débil y efímero, lo que ha convertido a las redes sociales y a una televisión cada vez más inclinada hacia el entretenimiento vacío en los nuevos instrumentos privilegiados de la comunicación política. Esto ha hecho que esta izquierda populista haya vuelto a la clásica tesis de Antonio Gramsci de hegemonía cultural, referida a la forma en la que las elites sociales, políticas, económicas y mediáticas dominaban sociedades culturalmente diversas, porque conseguían imponer como norma cultural universalmente aceptada su cosmovisión, es decir, sus creencias, sus valores o sus costumbres. Esta idea de hegemonía cultural se refería, por tanto, y de forma esencial, al instrumento intangible que justificaba como normal el orden de jerarquía y explotación de la elite. Por eso la propuesta populista es romper por medio de estos nuevos medios comunicativos el discurso llamado oficial ${ }^{28}$. Es decir, frente al viejo y caduco materialismo histórico del marxismo clásico, una nueva concepción de politización permanente y de considerar que los procesos de cambio social no se determinan exclusivamente en razón de los procesos económicos, sino que son esencialmente procesos políticos de confrontación de discursos. Es la victoria de la consustancialidad política sobre el viejo materialismo histórico del marxismo clásico.

Por eso, la forma de acabar con esta dominación cultural es la unificación de diferentes discursos en un único relato de la realidad, que debe ser aceptado por esa mayoría articulada a la que denominan pueblo. De ahí la importancia que esta nueva izquierda concede a la generación de pensamiento y a la comunicación política, que debe ser simplificada al máximo para generar un efecto deslegitimador de los discursos y narrativas "oficiales". Por eso su insistencia en asumir su condición de voz del pueblo.Frente a la insistencia típica del pensamiento liberal en la idea de que todos somos iguales ante la ley y la búsqueda de lo que une a las personas para poder conformar comu-

\footnotetext{
${ }^{28}$ C. FernÁNDEZ LiRia (2016), En defensa del populismo. Madrid, Libros La Catarata, pp. 5152. C. Rendueles y J. Sola (2015), Podemos y el populismo de Izquierdas. ¿Hacia una contra hegemonía desde el sur de Europa? Biblioteca Virtual. OMEGALfa, http://omegalfa.es/downloadfile.php?file=libros/podemos-y-el-populismo-deizquierdas.pdf. pp. 9-10.
} 
nidades políticas plurales y diversas basadas en el consenso, este populismo posmoderno de extrema izquierda hace de la diversidad y la multiplicidad un factor más de subversión, pues pretenden presentarse como verdadera voz de la multiplicidad de movimientos sociales que expresan la dialéctica dominador/dominado, es decir, que expresan esa lógica denunciada de violencia simbólica que, desde esta perspectiva ideológica, todavía sigue caracterizando a las democracias occidentales ${ }^{29}$.

Bajo el pretexto de una democracia social y de base, lo que realmente plantean es el ataque a la democracia liberal representativa tachándola de meramente formal, restando con ello legitimidad a sus cauces institucionales y a sus representantes elegidos. Es la anhelada subversión del orden liberal.

Pero conviene resaltar esa idea posmoderna de sustituir la vieja idea de lucha de clases por la de pluralidad de antagonismos, que pueden ser canalizados a través de una nueva oposición que enfrenta al pueblo, de donde emanan esas diversas demandas, y a los privilegiados, que impiden el reconocimiento de esas demandas bajo la idea de consenso hegemónico. Por tanto, ya no hay un único sujeto revolucionario, sino muchos: mujeres, pensionistas, afectados por las hipotecas, los inmigrantes indocumentados o en situación irregular, etc. Tantos, como demandas colectivas representen, por lo que el proceso político vive una tensión de radicalidad democrática permanente ${ }^{30}$. El populismo es así el cauce de canalización y agregación de esas demandas que no necesitan ser definidas, pues son, como dice Laclau, significantes vacíos que se irán llenando en el proceso de imposición de esa misma lógica de la razón populista ${ }^{31}$.

El populismo rompe con la idea de la democracia liberal entendida como orden racional en el que los conflictos se resuelven después de racionalizarlos. Lo sustituye por la idea de emociones colectivas. Todo se vuelve simbólico. La emoción lleva a la participación y también a que esa participación asuma formas irracionales, teatrales cuyo fin es el reconocimiento social,

${ }^{29}$ P. Bordieu, (2000), La dominación masculina. Barcelona, Anagrama; ID. (2003), Las estructuras sociales de la economía. Barcelona, Anagrama.

${ }^{30}$ I. ERREJón y CH. Mouffe (2015), Construir pueblo. Hegemonía y radicalización de la democracia. Barcelona, Icaria.

${ }^{31}$ E. LaClau (2005), La razón populista. México, FCE, p. 130. 
entre el grupo de pertenencia en el que los militantes populistas se incluyen. La primacía de lo emocional ${ }^{32}$, de lo pasional, habla de lo efímero, del problema de la duración ya que ésta depende de la capacidad para mantener esa emoción y esa irracionalidad que se construye dividiendo radicalmente el espacio público entre buenos y malos. La opinión pública es un mercado de generación de atención permanente.

En definitiva, esta razón populista se alcanza imponiendo su propio discurso, sea ajustado a la realidad o inventado. Ahora, en este lenguaje tan líquido se llama posverdad a lo que antes se conocía como mentira. Pero no son mentiras inocuas, sino conscientes y necesarias para crear esa tensión social y esa sensación de subversión social permanente sin la cual el populismo no podría vivir. Por eso, para este populismo la lucha política es, sobre todo, la lucha por la hegemonía cultural y por la dirección del debate y de la agenda pública. Esta construcción de una nueva verdad tiene por tanto la función de acabar con esa lógica de dominación cultural que atribuyen a las elites. Por eso, el populismo sitúa como eje central de su discurso la lucha contra el estatus quo del sistema democrático liberal.

En definitiva, el populismo es un camino rápido para alcanzar el poder o, por lo menos, para aproximarse mucho a él. Y ese sí que es un objetivo plenamente político. Ya afirmó Pareto en su conocida teoría de circulación de las elites, que en todas las sociedades la dirección política y administrativa es ejercida por una minoría organizada que va rotando en el poder incorporando algunos nuevos miembros por un sistema informal de cooptación ${ }^{33}$. Por tanto, este populismo parte de la base de que el acceso a la elite política es demasiado cerrado para que ellos puedan ser incorporados según los sistemas tradicionales de cooptación, por lo que la única forma de transitar hacia el verdadero poder político es "asaltar los cielos"34.

Aquí, sin embargo, los populistas no crean una realidad paralela, pues es-

\footnotetext{
${ }^{32}$ M. Arias maldonado (2016), La democracia sentimental. Politica y emociones en el siglo XXI. Barcelona, Indómita.

${ }^{33}$ V. PARETO, (1980) Forma y equilibrios sociales. Extracto del tratado de sociología general. Barcelona, Anagrama.

${ }^{34}$ La frase del líder de Unidos Podemos está tomada de una carta de Marx a Kugelmann de 12 de abril de 1871. Desde entonces es una frase recurrente del comunismo español.
} 
ta cerrazón elitista de la política es real, o cuanto menos así es percibida por buena parte de la sociedad. Por eso, la forma de derribar ese muro de entrada es el ataque y deslegitimación sistemática del estatus quo político, la socialización de la idea de unos políticos que ya no representan a los ciudadanos y que siguen su propia lógica de poder. Es esa clase política que cohabitaría, protegería e incluso integraría lo que Acemoglou y Robinson han llamado elites extractivas para referirse a esas elites que han establecido un sistema de apropiación de rentas para su exclusivo beneficio, actuando conforme a un sistema moral extremadamente laxo y con frecuencia rayano en la ilegalidad y la corrupción ${ }^{35}$.

La idea de elite extractiva expresa bien el desencanto e inseguridad que se han extendido por las sociedades democráticas occidentales. Tan acostumbradas a la opulencia, parece que se les había olvidado lo que es una crisis y las consecuencias que traen consigo. Es indudable que la crisis ha acabado con anteriores certidumbres y ha fulminado la credibilidad de unos partidos políticos tradicionales incapaces de ilusionar a los ciudadanos, a quienes demandan permanentes esfuerzos en razón de no se sabe bien qué imponderables inevitables: la competitividad, la eficiencia, la excelencia, el avance tecnológico, etc. Esta situación ha expandido una idea de ganadores y perdedores, unos reales y otros imaginados, entre los que se autoubican la mayoría de los nuevos líderes de esta izquierda populista que, sin embargo, se arrogan la representación falsa de un supuesto pueblo homogéneo, único, indiferenciado, movilizado a través del sentimiento, "de los que sufren", aunque ellos personalmente no hayan sufrido nada.

En todo caso, el auge de los populismos no puede esconder la debilidad de las democracias actuales, ni la crisis de representación por la que atraviesan. Tampoco se puede esconder que la tecnocracia y la simple comunicación política han acabado restando valor a las diferencias ideológicas, pues las ideas ceden ante la imagen que, supuestamente, parece que es lo que lleva a ganar elecciones. Los ciudadanos deberían, y sobre todo los políticos

35 D. Acemoglu y J.A. Robinson (2012) Por qué fracasan los países. Bilbao, Ediciones Deusto. El sentido general de esta obra recuerda otra más lejana en el tiempo y más centrada en el ámbito de lo ideológico que en el institucional como el primero. A. Minc, (1994) La nueva edad media. El gran vacio ideológico. Madrid, Temas de Hoy. 
deberían, preguntarse por qué tantos millones de personas quieren acabar con ellos y con el estatus quo que representan. La opción no puede seguir estando representada por unos partidos tradicionales que solo gestionan los asuntos públicos, y la crisis ha demostrado que encima no muy bien, y unos redentores vocacionales que apelan a la pasión y a la sentimentalización de la política como forma de alcanzar el poder, pero que son incapaces de hacer algo con él más allá de simplistas políticas de gestos. La democracia es frágil y también es aburrida. Cuando el sistema funciona, lo normal es que la mayoría de ciudadanos se ocupe de sus propias vidas dejando de lado nuestra dimensión de ciudadanos participantes en el escenario público. Pero cuando la situación es mala se define con facilidad unos enemigos a quienes culpar de todos los males: la globalización, los extranjeros, la casta, la elite, etc.

Hace años, la posibilidad de participar en el debate público era muy limitada; hoy es extraordinariamente amplia, pues basta con publicar un twitter de 280 caracteres para si eres suficientemente agresivo y radical poder hacerte famoso de forma rápida, por lo menos durante un minuto. En esto Twitter contradice a Andy Warhol cuando afirmó que en el futuro, todos serán famosos mundialmente por 15 minutos. Con Twitter 15 minutos son una eternidad.

En definitiva, se puede afirmar que el populismo no es una ideología ni siquiera delgada. Es un ropaje camaleónico y adaptativo, un discurso, una narrativa y una práctica política que consiste en la negación del consenso social y su sustitución por un relato de antagonismo radical y permanente entre una oligarquía imaginada y un pueblo irreal por homogéneo y compacto al que ellos dicen representar en exclusiva.

Pero el populismo es también un ropaje instrumental que encubre ideologías duras y las barniza a través de un determinado tipo de discurso, y de un proceso comunicativo basado en la polarización radical y permanente de la sociedad en un nosotros y un ellos. En otras palabras, es la utilización de la vía política para acabar con la política, o sea, con el consenso y la aceptación del otro como condiciones básicas y esenciales para que las personas puedan convivir de forma pacífica y democrática. No se puede olvidar que el mayor riesgo para la democracia es la dinámica de confrontación radical que divide a la sociedad en buenos y malos, ya que esa lucha solo se puede solucionar a 
través de la victoria total de unos y la derrota total de los otros. Este es el objetivo esencial del populismo y es, por ello, la utilización de la política para acabar con la política.

\section{CONCLUSIONES}

El populismo es un movimiento sociopolítico multiclasista que convierte a las masas populares, al llamado pueblo, en principal sujeto político, entendido en el sentido marxista de sujeto revolucionario. Pero el maniqueísmo pueblo/antipueblo no deja de esconder las técnicas de manipulación que los carismáticos líderes populistas hacen de ese pueblo, utilizando para ello una potente retórica de polarización social que apela también a un confuso nacionalismo, trasmutado hoy en una compleja formulación de un concepto de patriotismo sesgado y segmentado.

El populismo convive con diferentes ideologías porque es, ante todo, un discurso político que divide a la sociedad en dos campos antagónicos: pueblo y oligarquía. Este discurso es necesario para camuflar su carácter de movimiento iliberal.

Como discurso de justificación se dirige más a la parte emocional que a la intelectual de sus receptores, nutriéndose de esta forma de corrientes antiguas como el irracionalismo y el vitalismo filosóficos.

El populismo niega la libertad individual, pues considera que la sociedad es un todo integrado y armónico donde el individuo se debe adecuar al supremo interés de la nación. Quien no se integra es desprestigiado como antipatriota o antipueblo. Al utilizar esta forma de represión psicológica, el populismo puede convivir con un sistema formal de democracia constitucional, aunque siempre limitándola a unos límites puramente formales.

Para justificar esta limitación de la democracia el discurso político trata de inventar justificaciones en el sentido de presentarse a sí mismo como la verdadera democracia, como la "democracia real". Pero en cualquiera de sus formas, es un claro antagonismo de la democracia liberal representativa y de los conceptos de autonomía y libertad individual que conlleva. Su apuesta es por un Estado concebido de forma que tiene el deber de dirigir la sociedad 
gracias a la acción del líder, considerado como el gran conductor predestinado para dirigir los destinos de la nación, Pero el populismo une los destinos del líder a los del pueblo. Es decir, parte de una exaltación del pueblo como categoría suprema. Un pueblo idealizado liderado por el un caudillo que se enfrenta a los sectores antipopulares. Pero la realidad es que esta exaltación del pueblo no es más que un mecanismo de movilización y manipulación política dirigido a hacer creer a los sectores populares que esos líderes carismáticos son sus verdaderos defensores para que así acepten su dominio, convencidos de que actúan en su beneficio.

En definitiva, el populismo tiende a establecer en nombre del pueblo un nuevo sistema de caudillaje basado en unas clientelas urbanas agrupadas bajo el paraguas retóricamente protector de la sociedad civil. En realidad, es un muy simplista voluntarismo político arremolinado en torno a un conjunto de ideas-fuerza maniqueo y apelaciones globales al compromiso absoluto por parte de sus fieles, a quienes se conmina a creer en un cambio total, en una revolución imaginaria que alterará radicalmente la situación anterior, para dar paso a una nueva etapa idílica.

Como su realidad es imposible, estos populismos acaban apelando a la unanimidad política como forma de alcanzar esa revolución en marcha, y a quien no acepta se le tilda de traidor, de antipatriota, de anti-pueblo. Este enemigo es expulsado simbólicamente del espacio político, pero no se le elimina, lo que permite al populismo convivir con las formas democráticas. De hecho, estos populismos garantizan la concurrencia, guardándose formalmente apariencias de normalidad constitucional. Pero de una constitución adaptada a su universo ideológico, no la constitución preexistente a la que se le atribuye el carácter de instrumento de la elite, o emanación de un régimen político caduco y superado.

En concreto, el neopopulismo de extrema izquierda analizado es iliberal en sentido general y antiliberal en sentido estricto. Su ideología es clara y sus objetivos también: la desinstitucionalización de las democracias liberales como vía para la tan anhelada revolución que permita la construcción del mito de la sociedad socialista, aunque cada vez le sea más difícil definir esa vieja utopía. Por supuesto que esta terminología ha trasmutado, pues hoy se habla del socialismo del siglo XXI, de radicalidad democrática, etc. En defi- 
nitiva, de una nueva democracia expresada a través de su acceso al poder como verdaderos y únicos representantes del pueblo. Pero, el nuevo discurso utilizado no puede esconder que el sentido ideológico de esa concepción iliberal de la democracia sigue refiriéndose a las viejas conceptuaciones marxistas. 